\title{
O TEOR TESTEMUNHAL NO CONTO HELGA, DE LYGIA FAGUNDES TELLES: UM ESTUDO DE MEMÓRIA E IDENTIDADE
}

\author{
Tânia Maria Pereira SARMENTO-PANTOJA \\ Universidade Federal do Pará (UFPA) \\ nicama@ufpa.br \\ Kamila Rodrigues LIMA \\ Universidade Federal do Pará (UFPA) \\ milalima9@yahoo.com.br
}

Resumo: A literatura brasileira pósguerra é marcada por textos que tem como fundo um cenário violento, devido ao acumulo de catástrofes colecionadas no século XX. Neste trabalho buscamos analisar o teor testemunhal presente no conto Helga, de Lygia Fagundes Telles, bem com elucidar como as categorias memória e esquecimento funcionam como estratégias narrativas na tessitura de textos que apresentam marcas da Shoah na literatura brasileira.

Palavras-chave: Teor testemunhal. Helga. Lygia Fagundes Telles.

\begin{abstract}
The post-war Brazilian literature is marked by texts whose background a violent scenario, due to the accumulation of disasters collected in the twentieth century. In this paper we analyze the witness content in the tale Helga, by Lygia Fagundes Telles, as well as elucidate the categories memory and forgetting function as narrative strategies in the fabric of texts that have Shoah marks in Brazilian literature.
\end{abstract}

Keywords: Testimonial content. Helga. Lygia Fagundes Telles. 


\section{Introdução}

A literatura brasileira pós-guerra é marcada por textos que tem como fundo um cenário violento, devido ao acumulo de catástrofes colecionadas no século XX. Com isso, os escritores contemporâneos, em sua maioria, trazem em suas obras um forte teor testemunhal, que permite com que tomemos de exemplo as atrocidades ocorridas nas grandes tragédias para refletirmos e apurarmos essa recorrência na sociedade contemporânea.

Neste trabalho buscamos analisar o teor testemunhal presente no conto Helga, de Lygia Fagundes Telles, bem com elucidar como as categorias Memória e Esquecimento funcionam como estratégias narrativas na tessitura de textos que apresentam marcas da Shoah na literatura brasileira. No intento, faz-se necessário, a priori, esclarecer a opção pelo termo teor testemunhal em detrimento do termo literatura de testemunho na análise do referido conto.

Dentro da concepção de literatura de testemunho existem duas correntes que se diferenciam. A primeira refere-se à produção dos sobreviventes das catástrofes e dos genocídios, em especial da Shoah, termo da língua iídiche utilizado para definir o genocídio em massa dos judeus durante a Segunda Guerra Mundial. Na literatura de Shoah, o caráter literário da lugar ao real, afastando-a da ficção; a segunda não se limita à produção dos sobreviventes, mas toma-a de exemplo para levantar reflexões sobre a sociedade moderna por meio da ficção literária, aqui o caráter literário das obras toma o primeiro plano.

\section{O teor testemunhal no conto Helga}

Dentre as produções dos sobreviventes da Shoah, o conteúdo destes corpus se debruça em retratar a sobrevida que estes tiveram nos campos de concentração, toda tortura e aniquilamento sofrido pelos mesmos e seus iguais, através de um testemunho em sua maioria fragmentado. Nessas narrativas detectamos a suspensão dos direitos fundamentais do ser humano, pois os valores e os direitos do homem são violentamente suprimidos, nesses termos o sentido de humanidade é ferido. $\mathrm{O}$ sobrevivente sente a necessidade de 
testemunhar, para que o outro, ao tomar conhecimento do evento catastrófico, tome a experiência do sobrevivente como exemplo de luta contra a ocorrência de novas catástrofes que levem a tortura e ao extermínio em massa da raça humana. Deste modo, "no campo, uma das razões que podem impelir um deportado a sobreviver consiste em tornar-se uma testemunha" (AGAMBEN, 1942, p. 25). De acordo com Agamben (1942, p. 27), a testemunha pode ser representada por dois termos, em latim:

$\mathrm{O}$ primeiro, testis, de que deriva o nosso termo testemunha, significa etimologicamente aquele se põe como terceiro em um processo ou em um litígio entre dois contendores. $\mathrm{O}$ segundo, superstes, indica aquele que viveu algo, atravessou até o final um evento e pode, portanto, dar testemunho disso.

Assim, o corpus referente à narrativa de sobreviventes tanto pode considerar o testemunho daquele que viveu a violência, quanto daquele que conta a experiência do outro, nos dois casos predomina o registro da representação.

A segunda corrente não se limita aos testemunhos oriundos das experiências nos campos nazistas e reconhece marcas do autoritarismo e do universo concentracionário no Estado moderno. Através do caráter literário vislumbra marcas da violência na sociedade contemporânea. Desta maneira, "trata-se de descrever como as marcas da convivência com o horror inscrevem-se na forma literária, como os procedimentos de construção do texto aludem à catástrofe, entendida como aniquilamento.” (DE MARCO, 2004, p. 61). Neste momento, a linguagem assume o papel de mediadora de um trabalho reflexivo, em que o texto se desprende de qualquer compromisso com o real e assume seu caráter literário, porém sem banalizar a singularidade que recai sob as experiências perplexas oriundas das catástrofes históricas.

No interstício entre o objetivo e o literário, a literatura de teor testemunhal serve ao papel de aliar cultura e escrita. De acordo com Seligmann-Silva (TIBURI, 2011, p. 11)

O que aconteceu na teoria do testemunho foi uma revalorização desse nó entre o real e a linguagem. Essa visão testemunhal lança uma outra luz sobre o fenômeno da cultura. Hoje podemos dizer que toda manifestação cultural possui um elemento testemunhal. Aprendemos a perceber isso 
graças ao acúmulo de violências no século XX que, ao trincar a cultura e a linguagem, revelou esse magma testemunhal ${ }^{1}$.

Neste sentido, seguimos com a análise do conto Helga, buscando estabelecer como o caráter literário da narrativa de Lygia Fagundes Telles nos revela elementos da literatura de Shoah, através do alto teor testemunhal do conto em questão, carregado de imagens de violência e crueldade. Desta forma, ambientado no período da Segunda Guerra Mundial, a partir da lembrança da narrativa em $1^{\mathrm{a}}$ pessoa do protagonista da trama, o conto traz à tona marcas da violência e do aniquilamento do ser humano por outro da sua mesma espécie, evidenciando-se a intertextualidade entre a ficção no conto lygiano e o período histórico da Segunda Guerra Mundial (1939-1945).

Em linhas gerais, observamos que o conto lygiano nasceu de uma das atrocidades da guerra, oriunda de uma notícia que a autora leu em um jornal, daí partiu seu trabalho de ficção que teve como ponto inicial uma memória factual que Lygia guardou da segunda grande catástrofe da humanidade. Sobre este fato ela esclarece:

Um escritor português quis saber se o meu conto "Helga", que ele achou demasiado cruel, foi memória ou invenção. Metade memória e metade invenção, respondi. A memória estava na notícia que li num jornal, a página trazia algumas excentricidades da Segunda Guerra Mundial e entre essas estava aquela que me fisgou (...). A curta notícia que li no jornal era apenas essa e que me deixou estarrecida, meu Deus! na noite de amor ele pegou a perna - direita ou esquerda? - e desapareceu para sempre. Querendo me livrar da lembrança resolvi escrever o conto e aí começa a invenção (TELLES, 2007, p. 20-1 apud ROCHA, 2013, p. 589).

O enredo marcado por dois espaços, Brasil e Alemanha, e pela dupla identidade do narrador protagonista - "é bom dizer logo quem eu sou: Paulo Silva, brasileiro. Mas fui alemão" (TELLES, 171, p. 27), Paul Karsten, que nos revela a sua história, quando em uma de suas férias na Alemanha se depara com a eclosão da segunda grande guerra e é convocado a combater nas tropas alemãs.

$\mathrm{O}$ aço das metralhadoras sem carga encostado no peito banhado de suor. As bandeiras apoiadas no ombro no desfile diante de Hitler e Mussolini no estádio de Berlim, os alemães da América do Sul marchando logo atrás dos países sudetos e antes mesmo dos alemães da América do Norte.

\footnotetext{
${ }^{1}$ Entrevista concedida por Márcio Seligmann-Silva via e-mail à professora Márcia Tiburi, no ano de 2010. Publicado na revista Trama interdisciplinar. Disponível em: <http://editorarevistas.mackenzie.br/index.php/tint/article/download/ 3963/3150>.
} 
Amizade e amor foi lá que conheci, próximos e concretos. E o ódio também abstrato e longínquo, aos judeus, aos comunistas e a outras coisas mais que já esqueci. Tudo aconteceu porque a terceira viagem foi no verão de 1939. Não vou contar minha guerra, Polônia,França, Grécia, Rússia... (TELLES, 171, p. 28).

Visto como traidor no Brasil, ao fim da guerra, Paul Karsten instala-se na cidade de Dusseldorf, onde vem a conhecer Helga, jovem alemã que perdera uma perna no primeiro bombardeio de Hamburgo. Paul casa-se com Helga, mas na noite de núpcias rouba a perna mecânica da jovem e vende. De posse do capital, inicia um novo negócio e acaba fazendo fortuna.

O fato é que o roubo da perna de Helga vai além do valor financeiro, "mas [é] cedo para falar sobre a perna que vai exigir explicação. A perna envolve viagem, guerra, a perna vai tão além..." (TELLES, 171, p. 27). Através de uma linguagem rica em alegorias e associações, Lygia Fagundes Telles nos leva a refletir sobre o aniquilamento sofrido pelas minorias perseguidas no período da Segunda Guerra Mundial. Para tanto, destacamos que na tessitura do conto duas categorias são relevantes para compreendermos o valor testemunhal da narrativa, a saber: memória e esquecimento, ambas invocadas pelo narrador.

"Recordar-se ou esquecer é fazer um trabalho de jardineiro, selecionar, cortar." (AUGÉ,1998, p. 24 apud VILELA, 2012, p. 148-149). Desta forma, devemos atentar para o ponto de vista escolhido pelo narrador para contar a trama, pois sendo ele personagem protagonista, é o responsável por selecionar os fatos narrados, tratando de atenuar seu papel de carrasco de Helga, personagem esta, que não apresenta discurso direto no texto, tudo que sabemos sobre ela é apresentado pelo narrador através do discurso indireto. Para Paul Karsten, "sem esclarecimento tudo será apenas crueldade” (TELLES, 171, p. 27).

As estratégias de que Paul se utiliza para adiar sua confissão referente ao seu crime de guerra, não são suficientes para indicar o caráter algoz que recai sobre ele no decorrer da narrativa, pois em consonância com Vilela (2012, p. 149), "cada indivíduo, sob a força do acontecimento e da história, possui recordações e esquecimentos específicos que, de algum modo, indiciam quem ele é”. E foram as memórias de Paul, bem como seus fortuitos esquecimentos, que delinearam seu perfil de perpetrador no conto. A peculiaridade no 
conto lygiano é marcada pelo fato de termos um protagonista caracterizado como perpetrador, além deste ser o próprio narrador do enredo.

Neste sentido, Paul se recusa a lembrar detalhes, dentre os fatos, que lhe acometam sentimentos da culpa pelo que fez com sua esposa ao roubar a perna mecânica. O esquecimento é um aliado em retardar a grande marca que a guerra deixou no protagonista, ou melhor, a marca que ele deixara naquela que mais foi ferida. Lembremos juntamente com Vilela (2012, p. 148) que

Etimologicamente, o esquecimento é definido como a perda da recordação: o que se esquece não é a coisa em si mesma, os acontecimentos puros e simples, tais como ocorreram, mas a recordação, ou seja, uma impressão que perdura na memória (sendo a impressão o efeito que os objetos exteriores têm sobre os órgãos dos sentidos).

Nota-se que Paul recorda minúcias sobre as férias na Alemanha anteriores à eclosão da Segunda Guerra Mundial, o período em que serviu ao exército alemão e como procedeu após o término da guerra, mas é incapaz de lembrar qual das duas pernas Helga teria perdido no bombardeio, o que é inaceitável na compreensão do leitor atento ao caráter daquele que detém o ponto de vista da narração.

Curioso é que hoje já não consigo lembrar qual a perna que Helga perdera, se a direita ou a esquerda. E dizer que durante anos não houve dia nem hora que Helga não aparecesse no meu pensamento. Acha meu analista que os esquecimentos parciais são frequentemente formas sutis de autopunição (TELLES, 1971, p. 28)

Paul Karsten oscila entre suas memórias e os esquecimentos que lhe acometem referente ao período da guerra e o que ele fez após o fim desta. Ele ainda busca solucionar seu conflito interno por meio de consultas ao analista, o que traz um caráter confessional ao conto, muito característico às narrativas que apresentam personagens que vivenciaram, ainda que no tempo da ficção, grandes catástrofes ou genocídios, tanto estando na posição de vítima, quanto na posição do perpetrador, este último define bem a figura Paul Karsten. Ao buscar o analista, Paul já evidencia a dificuldade de pensar no período de suas férias de 1939 na Alemanha. Reconstituir os fatos exige esforço e os sentimentos são perturbadores, mesmo para o carrasco, pois este guarda o peso que seus atos imputaram sobre ele. "Como é difícil reconstituir os acontecimentos! Lembrar o ano em que tudo aconteceu já exige 
esforço. Distribuir os fatos pelos meses não consigo. Mas ordenar os sentimentos é para mim totalmente impossível" (TELLES, 1971, p. 32). Contudo, aos poucos as recordações de Paul revelam seu percurso de um jovem brasileiro de Vila Corinto para um perpetrador formado na escola da guerra.

Assim que acabou a guerra, vendi meu capacete e meu punhal com a cruz suástica a um funcionário brasileiro que até hoje não sei o que estava fazendo em Düsseldorf. Fomos para uma cantina onde me pagou uma cerveja e dele ouvi então coisas alarmantes: que a minha situação jurídica era nada mais, nada menos, do que a de um traidor, quer dizer, uns quinze anos de cadeia, por aí. Era só voltar e a condenação viria na certa. Recebi a notícia na hora errada porque naquela altura meu desejo maior era esquecer a guerra, encerrar as férias na Alemanha e tranquilamente voltar para Vila Corinto, casar por lá, cuidar do plantio, da criação e ajudar minha mãe que devia estar velha. Helga ainda não aparecera na minha vida e o hitlerismo e a guerra ainda não tinham me marcado para sempre. Ainda não". (TELLES, 1971, p 29)

Pelo caráter confessional da narrativa, entendemos que o analista que escuta Paul é cada um dos leitores do conto lygiano, recaindo sobre estes a escolha de condenar ou ser condescendente ao relatos do perpetrador. Antes que o leitor assuma uma posição faz-se necessário elucidar o verdadeiro crime de guerra que incide sobre o protagonista. "Paul Karsten cometeu seu crime de guerra, pessoal e por conta própria, mas fora do lugar e com a pessoa errada" (TELLES, 1971, p. 32).

Alemão impuro, filho de um certo Silva brasileiro, Paul cometeu um crime de guerra contra uma jovem alemã, ao ampliarmos nossa visão, podemos compreender que o crime fora cometido por um soldado alemão contra a própria nação pela qual lutara, pois feriu de maneira covarde e sem deixar possibilidade de reação a uma cidadã alemã de raça pura. Helga que já tinha seu corpo mutilado na guerra, ao perder sua perna em um bombardeio, teve na perna ortopédica comprada pelo pai, o farmacêutico Wolf, a possibilidade de reconstruir sua vida. Com o roubo, porém, a personagem sofre dupla mutilação.

A mutilação de Helga nos remete a tantas outras atrocidades cometidas por soldados alemães contra minorias, como judeus, ciganos e homossexuais. Helga perdera a família e a casa na guerra, restando a seu lado apenas seu pai e a possibilidade de liberdade que a perna mecânica lhe trouxera, o que já não era mais possível. Nesse momento, o hitlerismo de Paul 
marcara-o para sempre. E mais, seu hitlerismo teria contribuído para mutilar de forma cruel e premeditada a vítima indefesa, enquanto esta pensava naquela noite estar seguindo a marcha da vida, pelo fato de o casamento carregar com ele o significado de uma nova família, constituição de um novo lar, aliança.

Visto como traidor no Brasil, como já atestado, não considerado nem prisioneiro de guerra nem desertor, não restara a Paul outra alternativa que não fosse a solução final, a mesma que tiveram tantos que não puderam escolher pela vida nos campos de extermínio. Para retornar ao Brasil como um homem bem visto, capaz de constituir família e ter uma vida tranquila, o Paul Karsten alemão teve que deixar de existir para dar lugar a Paulo Silva Filho, sobre o qual não recairia qualquer crime de guerra imputado a Paul Karsten. Deste modo,

$\mathrm{O}$ ato de raça de senhor alemão aprendido nas aulas floridas dos cursos de 1936 foi praticado em plena paz por um pobre rapaz brasileiro contra uma pobre moça alemã. Engano ainda pensar que o fim de Paul Karsten foi uma solução. Alguns anos mais tarde, Paulo Silva Filho voltou para o Brasil anistiado e rico, mas voltou um homem de pouca fé e imaginação amortecida. A única maneira que encontrou de expiar o crime do jovem Paul foi tornar-se um cidadão exemplar. Hoje, o analista explica que simplesmente procuro e encontro, na insipidez da virtude, a punição de Paul Karsten e de seus camaradas (TELLES, 1971, p. 32).

Com a solução final de Paul Karsten, Paulo Silva Filho pode ter se expedido dos crimes incutidos sob o primeiro, mas não se desvinculou do passado que o assombra através da memória que a se fazer presente, mesmo quando esta sofre fissuras ou manipulase pelo esquecimento que recai sobre suas lembranças. Contudo, as recordações de Paul Karsten evidenciam a dupla identidade assumida pelo personagem, podemos pensar que a oscilação entre Paulo Silva e Paul Karsten passa por uma crise de lugar de pertença do personagem. No Brasil, como ele esclarece era filho de um "Silva brasileiro que não cheguei a conhecer” (TELLES, 1971, p. 27). Na Alemanha, não pertencia a raça ariana pura. A identidade construída sobre cada um é fruto das experiências vivenciadas em cada espaço que atuaram e protagonizaram. Na memória do narrador, um é testemunha do passado do outro. Deste modo,

A testemunha é um indivíduo que convoca as suas recordações para dar uma forma, isto é, um sentido, à sua vida, constituindo assim, para si, uma 
identidade. Cada um de nós é a testemunha da sua própria existência, relativamente à qual constrói uma imagem, omitindo certos acontecimentos, retendo outros, deformando ou acomodando ainda outros. Este trabalho pode sustentar-se através de documentos (traços materiais), mas ele é por definição solitário. (TODOROV apud VILELA, 2012, p. 152).

Assim, Paul é testemunha primária tanto do genocídio da Segunda Guerra Mundial, período no qual serviu ao exército germânico, quanto do aniquilamento de Helga, já violada anteriormente em uma tragédia ocasionada pela guerra, enquanto Paulo se apresenta como aquele que conta a experiência do outro. Lygia Fagundes Telles, testemunha de sua época, consegue com maestria trazer para um texto contemporâneo marcas de uma época que não pode ser esquecida.

\section{Conclusão}

Em Helga, temos um conto marcado por forte teor testemunhal, por ser permeado de imagens violentas e aludir ao período de guerra. Ademais, a narrativa não deixa a desejar no caráter literário, bem como proporciona uma instigante reflexão sobre a capacidade de aniquilação que o ser humano lança sobre sua própria espécie, bem como nos põe a pensar que este mesmo ser humano é o único agente capaz de evitar e ocorrência de novas catástrofes. Desse modo, as narrativas de testemunho, bem como as narrativas que são carregadas de teor testemunhal, dentre as quais se enquadra o conto Helga, têm o papel de proporcionar ao ser humano a consciência de tomar essas narrativas como exemplo para intervir na sociedade, de modo a não permitir que o sentido de humanidade seja ferido e nem que a violência e a intolerância sejam protagonistas da nossa história.

\section{Referências}

AGAMBEN, Giorgio. O que resta de Auschwitz: o arquivo e a testemunha. Tradução Selvino J. Assmann. São Paulo: Boitempo, 2008.

DE MARCO. Valéria. A literatura de testemunho e a violência de estado. Lua Nova: $\mathrm{N}^{\mathrm{o}}$ 64, São Paulo, 2014. 
ROCHA, Fátima. Invenção e memória em Lygia Fagundes Telles. Cadernos do CNLF, Vol. XVII, Nº5. Rio de Janeiro: CiFEFiL, 2013.

TIBURI, Márcia. Entrevista com Márcio Seligmann-Silva. In. TRAMA INTERDISCIPLINAR - v. 2 - n. 1, São Paulo: Editora Mackenzie, 2011. Disponível em: <http://editorarevistas.mackenzie.br/index.php/tint/article/download/3963/3150>.

TELLES, Lygia Fagundes. Antes do Baile Verde: contos. 2 ed. Rio de Janeiro: INL, 1971.

VILELA, Eugenia. Do testemunho. Princípios, v. 19, n. 31. Jan-Jun, 2012 